grams: validation with autopsy findings. Circulation 1987; $75: 565$.

22. Rao PS. ECG changes following percutaneous balloon dilata tion of pulmonic stenosis [Abstract]. J Electrocardiol 1987; 20:70.

23. Battler A, Froelicher VF, Gallagher KP, Kumada T, McKown $\mathrm{D}$, Kemper WS, Ross Jr J. Effects of changes in ventricular size on regional and surface QRS amplitudes in the conscious dog. Circulation 1980;62:174.
24. Maron BJ. Structural features of the athlete heart as defined by echocardiography. J Am Coll Cardiol 1986;7:190.

25. Nemati M, McCaughan D, Doyle JT, Pipberger HV. The influence of constitutional variables on orthogonal electrocardiograms of normal women. Circulation 1977;56:989.

26. Horton JD, Sherber HS, Lakatta EG. Distance correction for precordial electrocardiographic voltage in estimating left ventricular mass. An echocardiographic study. Circulation 1977;55:509.

\title{
Radionuclide determination of the relationship between left ventricular contractile state and ejection fraction
}

\begin{abstract}
To determine whether the relationship between various measures of left ventricular (LV) contractile state and ejection fraction (EF) is linear in man, we studied 30 patients during right atrial pacing over a range of loading conditions. With the use of micromanometer $L V$ pressures and radionuclide $L V$ volumes, pressure-volume $(P-V)$ loops were generated for each loading condition. Then isochronal, instantaneous P-V data points were obtained by linear regression analysis to attain the maximum slope $\left(E_{\max }\right)$ of these time-varying isochrones. Other measures of LV end systole were also used to calculate end-systolic P-V relations in a similar fashion, and indirect P-V relations were obtained from the linear regression analysis of brachial artery peak pressure vs minimum LV volume data points. When the slopes of these LV contractile measures were compared to the radionuclide LV EFs, the linear correlation coefficients ranged from 0.53 to 0.67. After natural log transformation of the $L V$ contractile state and EF data, the correlation coefficients for the polynomial curve fits ranged from 0.80 to 0.88 . When the correlation coefficients for the polynomial curve fits of the natural log transformed data were compared to those for the linear regression analyses of the raw data, significant improvements were evident $(p<0.05)$. Thus the relationship between various measures of LV contractlle state and EF obtained with radionuclide angiography is best approximated by a complex, curvilinear relationship that is due, in part, to the wide range of LV contractile states within the relatively narrow normal range of LV ejection fractions. (AM HEART J 1988;116:790.)
\end{abstract}

Mark R. Starling, MD, Milton D. Gross, MD, Richard A. Walsh, MD, G. B. John Mancini, MD, and Ralph Blumhardt, MD. Ann Arbor, Mich., and San Antonio, Texas

From the Divisions of Cardiology and Nuclear Medicine, University of Michigan and Veterans Administration Medical Centers; and the University of Texas Health Science Center.

Supported by National Institutes of Health Grant R01-HL36450, from the National Heart, Lung, and Blood Institute, Bethesda, Md., and by the Veterans Administration, Washington, D.C. Dr. Starling is the recipient of National Institutes of Health Research Career Development Award No. K04-HL01787 from the National Heart, Lung, and Blond Institute, Bethesda, Md.

Received for publication Jan. 19, 1988; accepted May 6, 1988.

Reprint requests: Mark R. Starling, MD, University of Michigan, Dept. of Internal Medicine, Cardiology Section, VA Medical Center, 2215 Fuller Rd., Ann Arbor, MI 48105.
The linear relationship between left ventricular (LV) end-systolic pressure vs volume (P-V) data points obtained from multiple loading conditions has been demonstrated in excised, supported LV and conscious animal preparations to be a measure of LV contractile state. ${ }^{1-6}$ The theoretic relationship between measures of LV contractile state and shortening characteristics, measured hy stroke volume or ejection fraction (EF) has been predicted to be curvilinear. ${ }^{3}$ Nivatpumin et al. ${ }^{7}$ have shown in man 
that the maximal P-V ratio obtained from a single beat has a curvilinear relationship with LV EF. This single-beat ratio, however, may be sensitive to loading conditions in addition to LV contractile state..$^{8-10}$ In contrast, invasive and noninvasive studies in $\operatorname{man}^{11,12}$ have reported a linear relationship between measures of LV contractile state calculated from multiple loading conditions and LV EF values. A linear relationship, however, does not incorporate low LV EF values, and therefore a curvilinear function might better represent this relationship over the full range of $\mathrm{LV}$ contractile states and EF values., ${ }^{3,11}$ Whether the relationship between $\mathrm{LV}$ contractile state and EF is optimally predicted by a linear or curvilinear function in man has not been established. Moreover, whether various measures of LV contractile state all have a comparable relationship with shortening characteristics has also not been defined. Accordingly, the purpose of this investigation was to determine whether the relationship between various measures of $\mathrm{LV}$ contractile state and $\mathrm{EF}$ obtained with radionuclide angiography is optimally predicted by a simple linear or by a more complex, curvilinear function in man.

\section{METHODS}

Patlents. The patient population consisted of 30 patients, 16 normal subjects, nine patients with aortic regurgitation, one patient with mitral regurgitation, two patients with cardiomyopathy, and two patients with a prior myocardial infarction. There were 23 men and seven women, with an age range of 23 to 71 years (mean $48 \pm 11$ [SD] years). Each patient was referred for diagnostic right and left heart catheterization to establish the presence or absence of coronary artery disease or to establish the hemodynamic severity of his/her cardiovascular disease. Each patient gave written informed consent for this investigation on a form approved by the Human Studies Committee at the University of Michigan or Veterans Administration Medical Centers, Ann Arbor, Mich., or the University of Texas Health Science Center, San Antonio, Texas. Eight patients were taking no medication, while the remaining 22 patients were taking one or more of the following: diuretics (eight patients), beta-adrenergic blocking agents (four patients), $\mathrm{Ca}^{++}$-entry blocking agents (five patients), vasodilators (six patients), or nitrate preparations (15 patients). All medications were discontinued 24 to 48 hours prior to cardiac catheterization. Twenty-eight of the 30 patients had normal coronary arteriograms, while the two patients with a prior myocardial infarction had single-vessel coronary artery disease with an occluded vessel to the previously infarcted myocardial region.

Protocol. After completion of the diagnostic catheterization, each patient entered the protocol, which consisted of the simultaneous acquisition of micromanometer mea- sured LV and ascending aortic pressures and fluid measured brachial artery pressures with gated equilibrium radionuclide angiograms under control conditions and during methoxamine and nitroprusside infusions. The average methoxamine infusion was $761 \pm 781$ (SD) $\mu \mathrm{g} /$ min, and the mean nitroprusside infusion was $79 \pm 93$ $\mu \mathrm{g} / \mathrm{min}$. Right atrial pacing was used to maintain heart rate constant during all three loading conditions. Steady state was defined as a $10 \mathrm{~mm} \mathrm{Hg}$ or less variation in the micromanometer and fluid pressure measurements during each radionuclide acquisition.

Hemodynamics. Twenty cardiac cycles of a simultaneous electrocardiogram (ECG), micromanometer LV (200 $\mathrm{mm} \mathrm{Hg}$ and $50 \mathrm{~mm} \mathrm{Hg}$ scales) and ascending aortic pressures (200 $\mathrm{mm} \mathrm{Hg}$ scale), the first derivative of $\mathrm{LV}$ pressure $(\mathrm{dP} / \mathrm{dt})$, and fluid brachial artery pressure $(200$ $\mathrm{mm} \mathrm{Hg}$ scale) were recorded at the beginning, middle, and end of each radionuclide acquisition at $100 \mathrm{~mm} / \mathrm{sec}$ paper speed with an Electronics for Medicine VR-12 or 16 physiologic recorder (Electronics for Medicine/Honeywell Inc., Pleasantville, N.Y.). Offset measurements were made for both the micromanometer and fluid pressure signals following each hemodynamic recording to guarantee stability of the zero reference.

The micromanometer $\mathrm{LV}$ and ascending aortic pressures and fluid brachial artery pressures were manually averaged for each radionuclide acquisition to obtain average pressure waveforms. The average micromanometer $\mathrm{LV}$ pressure waveform was then hand digitized with a Calcomp 9100 inductance tablet interfaced to an IBM PC computer (IBM Corp., Purchase, N.Y.) throughout the $R$ - $R$ interval beginning at the peak of the $R$ wave, with the use of a program developed in our laboratory. This program provides instantaneous LV pressure and the first derivative of $\mathrm{LV}$ pressure $(\mathrm{dP} / \mathrm{dt})$ at a variable sampling frequency. The LV pressures were sampled at $5 \mathrm{msec}$ intervals for this investigation. ${ }^{13}$

Equilibrium radionuclide angiography. Gated equilibrium radionuclide angiograms were obtained following in vivo red blood cell labeling with $30 \mathrm{mCi}$ of technetium$99 \mathrm{~m}$ at $30 \mathrm{msec} /$ frame throughout the R-R interval for 500 cardiac cycles. A $2 \mathrm{ml}$ blood sample was drawn during the middle of each radionuclide acquisition and was later counted for 2 minutes. The time delay between drawing and counting the blood sample was recorded for decay correction. Measurements were made on each patient to calculate the distance from the gamma scintillation camera in the left anterior oblique (LAO) position to the $\mathrm{LV}$ center of mass for attenuation correction, by means of anatomic landmarks and a simple geometric technique previously validated in this laboratory. ${ }^{14,15}$

Radionuclide LV volumes were calculated frame-byframe for each of the three loading conditions with a hand-drawn region-of-interest technique and attenuation correction. ${ }^{14,15}$ Briefly, on the background subtracted and smoothed images, an $L V$ region-of-interest was drawn by the operator to encompass the $\mathrm{LV}$ but to exclude the left atrium. These $L V$ counts were then normalized for frame duration, cardiac cycles, a decay-corrected plasma blood 
Table I. Hemodynamic data $(\mathbf{n}=30)$

\begin{tabular}{|c|c|c|c|}
\hline & Control & Methoxamine & Nitroprusside \\
\hline \multicolumn{4}{|c|}{ Heart rate (beuls/min) } \\
\hline $\mathrm{A}^{*}$ & $78 \pm 12(\mathrm{SD})$ & $76 \pm 12$ & $83 \pm 13$ \\
\hline $\mathrm{B}^{\dagger}$ & $79 \pm 13$ & $78 \pm 13$ & $83 \pm 13$ \\
\hline $\mathrm{C} \ddagger$ & $80 \pm 14$ & $78 \pm 15$ & $83 \pm 14$ \\
\hline \multicolumn{4}{|c|}{ Brachial artery peak pressure $(\mathrm{mm} \mathrm{Hg})$} \\
\hline A & $141 \pm 19$ & $179 \pm 21$ & $113 \pm 21$ \\
\hline B & $139 \pm 18$ & $183 \pm 20$ & $114 \pm 23$ \\
\hline $\mathrm{C}$ & $140 \pm 15$ & $184 \pm 20$ & $114 \pm 22$ \\
\hline \multicolumn{4}{|c|}{ Ascending aortic peak/dicrotic notch pressures ( $\mathrm{mm} \mathrm{Hg}$ ) } \\
\hline A & $129 \pm 19 / 98 \pm 25$ & $168 \pm 25 / 128 \pm 26$ & $100 \pm 20 / 79 \pm 19$ \\
\hline $\mathrm{B}$ & $128 \pm 21 / 100 \pm 17$ & $173 \pm 21 / 131 \pm 23$ & $100 \pm 21 / 80 \pm 19$ \\
\hline $\mathrm{C}$ & $127 \pm 16 / 103 \pm 12$ & $173 \pm 20 / 134 \pm 24$ & $100 \pm 21 / 81 \pm 19$ \\
\hline \multicolumn{4}{|c|}{ Left ventricular peak/end-diastolic pressures $(\mathrm{mm} \mathrm{Hg})$} \\
\hline A & $133 \pm 18 / 15 \pm 6$ & $172 \pm 29 / 22 \pm 10$ & $103 \pm 20 / 8 \pm 5$ \\
\hline B & $131 \pm 20 / 14 \pm 8$ & $174 \pm 22 / 21 \pm 9$ & $104 \pm 20 / 8 \pm 5$ \\
\hline $\mathrm{C}$ & $131 \pm 17 / 13 \pm 6$ & $176 \pm 20 / 21 \pm 9$ & $103 \pm 20 / 8 \pm 5$ \\
\hline
\end{tabular}

*A = beginning of each radionuclide acquisition.

$\dagger \mathrm{B}=$ middle of cach radionuclide acquisition.

$\downarrow C=$ end of each radionuclide acquisition.

Table II. Hemodynamic data $(n=30)$

\begin{tabular}{lcccccccc}
\hline & $\begin{array}{c}H R \\
(\text { beats } / \mathrm{min})\end{array}$ & $\begin{array}{c}\mathrm{BaP} \\
(\mathrm{mm} \mathrm{Hg})\end{array}$ & $\begin{array}{c}\text { Badi } \\
(\mathrm{mm} \mathrm{Hg})\end{array}$ & $\begin{array}{c}A o P \\
(\mathrm{~mm} \mathrm{Hg})\end{array}$ & $\begin{array}{c}\text { Aodi } \\
(\mathrm{mm} \mathrm{Hg})\end{array}$ & $\begin{array}{c}L V P \\
(\mathrm{~mm} \mathrm{Hg})\end{array}$ & $\begin{array}{c}L V E D P \\
(\mathrm{~mm} \mathrm{Hg})\end{array}$ & $\begin{array}{c}(+) d P / d t m a x \\
(\mathrm{~mm} \mathrm{Hg} / \mathrm{sec})\end{array}$ \\
\hline Control & $79 \pm 13$ & $129 \pm 41$ & $92 \pm 16$ & $126 \pm 16$ & $101 \pm 14$ & $130 \pm 16$ & $15 \pm 6$ & $1123 \pm 233$ \\
Methoxamine & $79 \pm 13$ & $176 \pm 42 \dagger$ & $118 \pm 22 \dagger$ & $171 \pm 21 \dagger$ & $131 \pm 20 \dagger$ & $174 \pm 22 \dagger$ & $23 \pm 9 \dagger$ & $1369 \pm 291^{*}$ \\
Nitroprusside & $\mathbf{8 2} \pm 14$ & $113 \pm 21 \dagger$ & $75 \pm 21 \dagger$ & $100 \pm 20 \dagger$ & $80 \pm 18 \dagger$ & $103 \pm 19 \dagger$ & $9 \pm 5 \dagger$ & $1208 \pm 292$ \\
\hline
\end{tabular}

$\mathrm{HR}=$ heart rate; $\mathrm{BaP}=$ brachial artery peak pressure; $\mathrm{Badi}=$ brachial artery dicrotic notch pressure; $\mathrm{AoP}=$ aortic peak pressure; Aodi $=$ aortic dicrotic notch pressure; LVP = left ventricular peak pressure; LVEDP $=$ left ventricular end-diastolic pressure. ${ }^{*} p<0.05$.

$\dagger p<0.001$ vs control.

sample counts. With the calculated distance from the gamma scintillation camera in the LAO projection and assuming a linear attenuation coefficient of $0.15 \mathrm{~cm}^{-1}$ for technetium-99m in water, ${ }^{14-17}$ the attenuation correction factor was calculated. The $L V$ volume indices were then multiplied by this attenuation correction factor to obtain absolute LV volumes.

Calculation of $E_{\max }$ and other P-V relations. With the use of the corresponding $\mathrm{LV}$ pressure measurements and radionuclide $L V$ volumes, $P-V$ loops for each of the three loading conditions were constructed. Then, isochronal instantaneous P-V data points from each of the three loading conditions were obtained by linear regression analysis beginning at the $R$ wave and continuing throughout the cardiac cycle. The maximum slope of these time-varying isochrones was defined as the maximum time-varying elastance $\left(\mathrm{E}_{\mathrm{max}}\right)$. Additional definitions of i $v$ enc syswoie were used to calculate end-systolic $P-V$ relations. These additional definitions of end-systole were the time of the maximum $\mathrm{P}-\mathrm{V}$ ratio (maxPV), which occurs at the left uppermost corner of each of the P-V loops; the time of minimum LV volume (minPV); the time of peak $(-) \mathrm{dP} / \mathrm{dt}[(-) \mathrm{dP} / \mathrm{dtPV}]$; and the time of zero systolic flow, which was approximated by the central aortic dicrotic notch (AodiPV). To calculate the endsystolic $\mathrm{P}-\mathrm{V}$ relations for the first three of these definitions of end systole, the corresponding P-V data points from the hand-digitized micromanometer $L V$ pressure waveform and radionuclide derived $L V$ volume curve from each of the three loading conditions, which corresponded in time to the definitions of end systole, were derived by linear regression analysis to obtain a slope value. For the AodiPV slope calculations, however, the actual aortic dicrotic notch pressures were used. The indirect P-V relations were obtained from the linear regression analysis of brachial artery peak $(\mathrm{BaP})$ pressure vs minimum $\mathrm{LV}$ volume (minV) data points from each of the three loading conditions. LV EF was calculated in the standard fashion with the use of the radionuclide absolute $\mathrm{LV}$ end-diastolic and end-systolic volumes.

Statistical analysis. The raw and natural log-transformed $\mathrm{LV}$ contractile slope values for $\mathrm{E}_{\max }$, the end- 


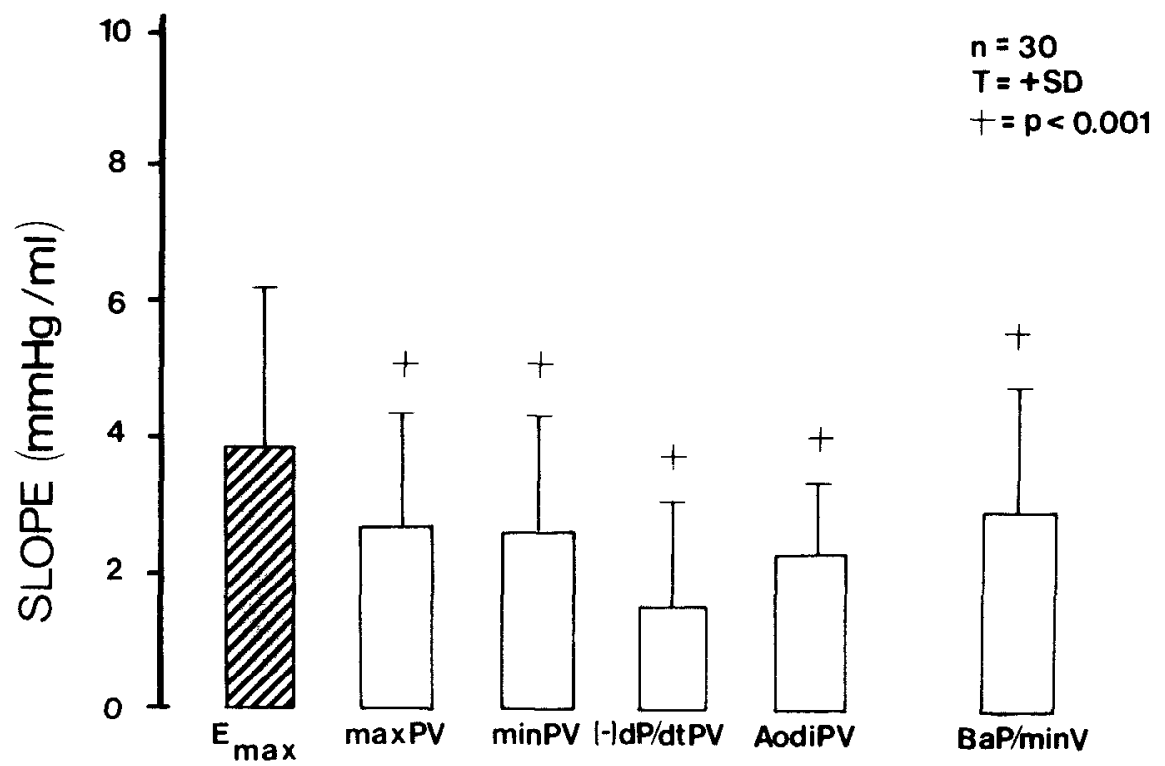

Fig. 1. The isochronal $\mathrm{E}_{\mathrm{max}}$ slope value (cross-hatched bar) is compared to the other end-systolic P-V and indirect P-V relations (open bars). The hars represent the mean $\pm 1 \mathrm{SD}$. Significant differences are shown.

systolic $\mathrm{P}-\mathrm{V}$ relations, the indirect $\mathrm{P}-\mathrm{V}$ relations, and $\mathrm{LV}$ EF data were compared by linear regression analysis and polynomial curve fitting. Correlation coefficients for each of these LV contractile state and EF comparisons were compared by Fisher's $Z$ transformation. The mean values for $E_{\max }$, the end-systolic P-V relations, and the indirect $P-V$ relations are presented as the mean \pm 1 standard deviation and were compared by an analysis of variance. When a significant $F$ statistic was obtained, $t$ tests with a Bonferroni correction were performed to identify where these differences occurred. Similar comparisons were performed for LV, ascending aortic, and hrachial artery pressures obtained during the beginning, middle, and end of each radionuclide acquisition to establish whether hemodynamic stability existed during each radionuclide acquisition, and for these pressures under the control condition and during the methoxamine and nitroprusside infusions to establish whether differences in these hemodynamic variables occurred between conditions. A probability value of 0.05 or less was considered significant.

\section{RESULTS}

Hemodynamic data (Tables I and II). During each radionuclide acquisition, a hemodynamic steady state was maintained, as shown in Table I. Notably, heart rate, brachial artery pressure, ascending aortic pressure, and LV pressure did not differ significantly between the beginning, middle, and end of each radionuclide acquisition.

In contrast, as shown in Table II a significant hemodynamic effect was produced by the methoxamine and nitroprusside infusions in comparison to control. Because of right atrial pacing, heart rate did not differ significantly between the three loading conditions. However, brachial artery, ascending aortic, and LV pressures increased during the methoxamine infusion ( $p<0.001$ for each) and decreased during the nitroprusside infusion ( $p<0.001$ for each) compared to control. There was an increase in $(+) \mathrm{dP} / \mathrm{dtmax}$ during the methoxamine infusion $(p<0.05)$, but there was no significant effect of nitroprusside on the rate of $\mathrm{LV}$ pressure development compared to control.

Comparison of various measures of LV contractile state to $E_{\max }$. The average isochronal $\mathrm{E}_{\max }$ slope value for the 30 patients was $3.94 \pm 2.24 \mathrm{~mm} \mathrm{Hg} / \mathrm{ml}$, and it was underestimated by the other end-systolic and indirect P-V relations ( $p<0.001$ for all, Fig. 1). The $\max P V$ relations averaged $2.61 \pm 1.73 \mathrm{~mm} \mathrm{Hg} / \mathrm{ml}$, the $\min P V$ relations averaged $2.50 \pm 1.73 \mathrm{~mm} \mathrm{Hg} /$ $\mathrm{ml}$, the $(-) \mathrm{dP} / \mathrm{dtPV}$ relations averaged $1.56 \pm 1.71$ $\mathrm{mm} \mathrm{Hg} / \mathrm{ml}$, and the AodiPV relations averaged $2.16 \pm 1.38 \mathrm{~mm} \mathrm{Hg} / \mathrm{ml}$. The average $\mathrm{BaP} / \mathrm{minV}$ relation was $2.69 \pm 1.90 \mathrm{~mm} \mathrm{Hg} / \mathrm{ml}$.

The average isochronal $\mathrm{E}_{\max }$ extrapolated volumeaxis intercept was $47 \pm 93 \mathrm{ml}$. Although the mean unstressed volume $\left(V_{0}\right)$ values for the other endsystolic and indirect $P-V$ relations were less than that for $E_{\max }$, they did not underestimate it significantly, due to the wide variance in these values $(17 \pm 94,27 \pm 149,-2 \pm 148,-1 \pm 57$, and $-2 \pm$ $49 \mathrm{ml}$, respectively). 


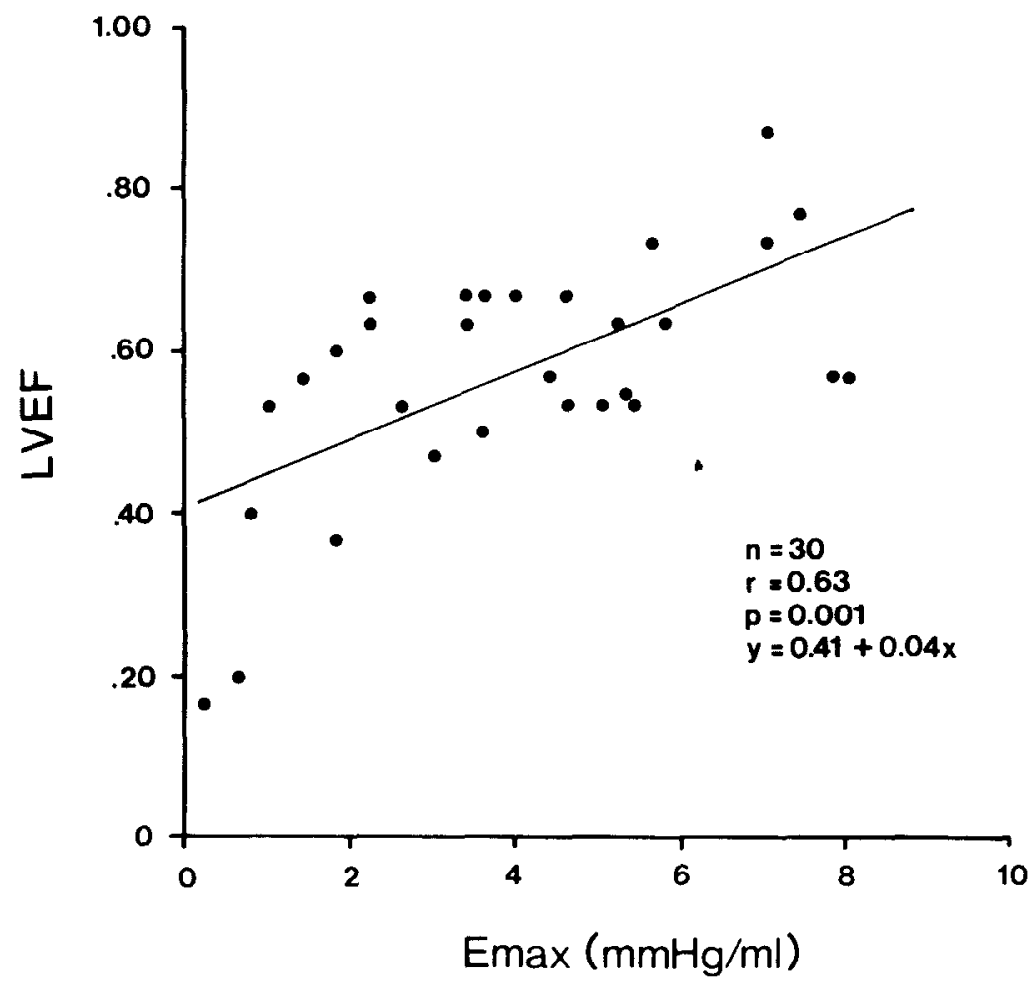

Fig. 2. The individual left ventricular ejection fraction ( $L V E F)$ values (on the ordinate) and their corresponding isochronal $\mathrm{E}_{\max }$ slope values (on the abscissa) are compared by linear regression analysis. The line of best fit, correlation coefficient $(r)$, and regression equation are shown.

Table III. Correlation between measures of $\mathrm{LV}$ contractile function and ejection fraction $(\mathrm{n}=30)$

\begin{tabular}{|c|c|c|c|c|c|c|}
\hline & $E_{\max }$ & $\max P V$ & $\min P V$ & $(-) d P / d t P V$ & AodiPV & $B a P / \min V$ \\
\hline \multicolumn{7}{|l|}{ Raw data } \\
\hline Linear regression & 0.63 & 0.64 & 0.67 & 0.20 & 0.53 & 0.65 \\
\hline Polynomial curve fit & 0.71 & 0.70 & 0.71 & 0.20 & 0.66 & 0.70 \\
\hline \multicolumn{7}{|c|}{ Natural log transformed data } \\
\hline Linear regression & 0.80 & 0.79 & 0.78 & 0.23 & 0.77 & 0.79 \\
\hline Polynomial curve fit & $0.84 \dagger$ & $0.88^{*}$ & $0.83 \dagger$ & 0.24 & $0.80^{*}$ & $0.86^{*}$ \\
\hline
\end{tabular}

$E_{\max }$ - maximum time-varying elastance; $\operatorname{maxPV}=$ time of maximum $\mathrm{P}-\mathrm{V}$ ratio; $\min P V=$ time of minimum $\mathrm{LV}$ volume; AodiPV $=$ time of zero systolic flow approximated by the central aortic dicrotic notch; $\mathrm{BaP}=$ brachial artery peak pressure; $\operatorname{minV}=$ minimum $L V$ volume. ${ }^{*} p \leq 0.05$.

$t_{p}<0.10$ vs linear regression of raw data.

Comparison of LV contractile state and EF (Table III). The correlation coefficients between measures of $\mathrm{LV}$ contractile state and EF are shown in Table III, and they are displayed for isochronal $\mathrm{E}_{\max }$ in Figs. 2 to 4 . As demonstrated in Fig. 2, the correlation coefficient for the linear regression of isochronal $\mathrm{E}_{\max }$ and $\mathrm{EF}$ was $r=0.63(p=0.001)$. When a polynomial curve fit was applied to these data, the correlation coeffivicui inpiuveri io $1=0.71$ ( $p<0.001$, Fig. 3$)$. When the isochronal $\mathrm{E}_{\max }$ slope values and $\mathrm{LV}$ EF data were natural log transformed, the correlation coefficient for the linear regression of these data improved to $r=0.80$ ( $p<0.001$, Fig. 4). A further improvement in the correlation coefficient to $r=0.84$ ( $p<0.001$, Fig. 4) was observed when a polynomial curve fit was applied to the natural log transformed data. When the correlation coefficients for the linear regression of the raw data and the polynomial curve fit of the natural log transformed data were compared, there was a marginal improvement in correlation between these data $(0.10>p>0.05)$.

Similar comparisons between the end-systolic P-V slope value relations and LV EF data demonstrated a progressive improvement in the correlation 


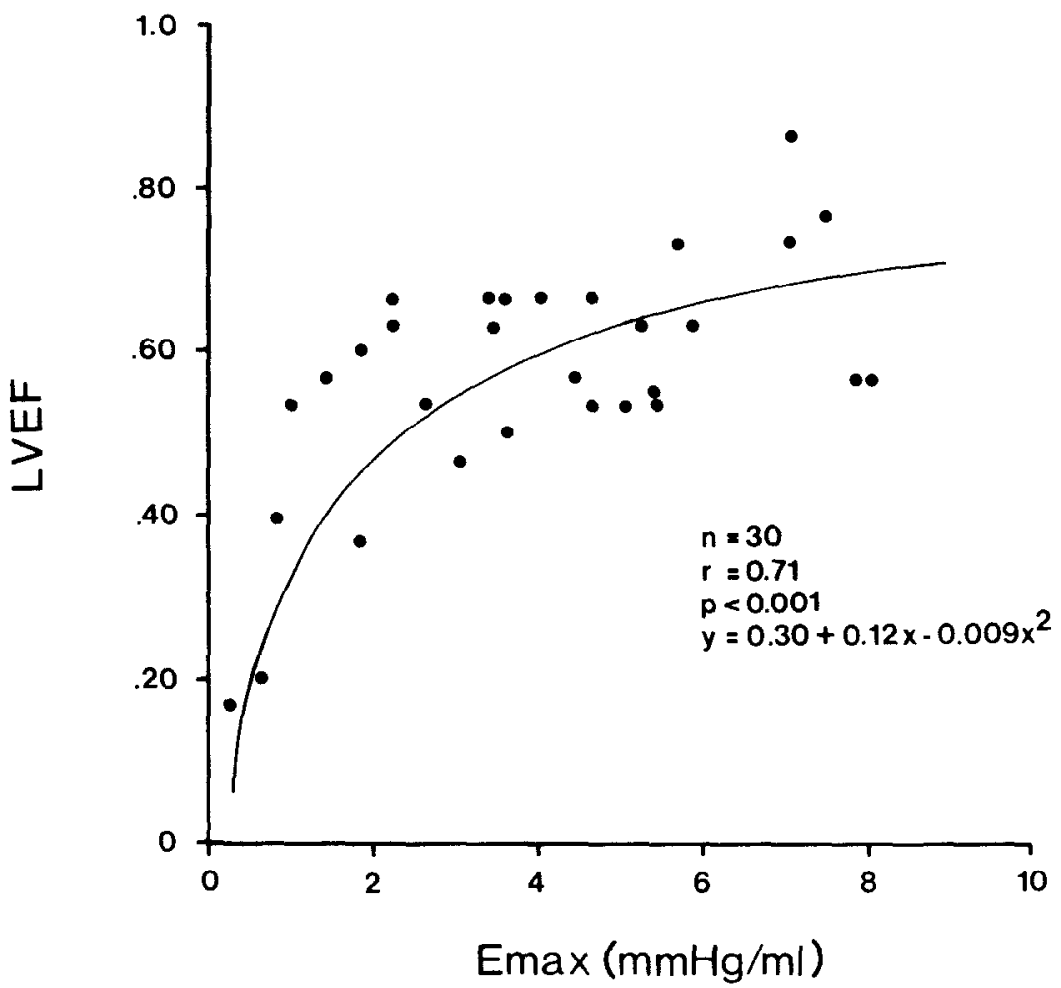

Fig. 3. In a format similar to that of Fig. 2, the LVEF and isochronal $\mathrm{E}_{\max }$ slope values are compared by means of a polynomial curve fit.

coefficients from the linear regression of the raw data to the polynomial curve fit of the natural $\log$ transformed data ('Table III). A significant improvement in the correlation coefficients was noted for the maxPV and the AodiPV relations $(p<0.05$ for both), while a marginal improvement was noted for the minPV relations $(0.10>p>0.05)$. The correlation coefficients between the $(-) \mathrm{dP} / \mathrm{dtPV}$ relations and LV EF data remained consistently poor.

The indirect $\mathrm{P}-\mathrm{V}$ relations $(\mathrm{BaP} / \mathrm{minV})$ also demonstrated a progressive improvement in correlation coefficients between the $\mathrm{BaP} / \mathrm{minV}$ slope values and the LV EF data. Compared to the linear regression analysis of the raw data, the polynomial curve fit of the natural $\log$ transformed data significantly improved the correlation coefficient between these data $(p<0.05)$.

\section{DISCUSSION}

The data in the present investigation indicate that the LV maximum time-varying elastance $\left(\mathrm{E}_{\max }\right)$ slope values have only a weak linear relationship with their corresponding LV EFs. The relationship between isochronal $E_{\max }$ slope values and LV EF is more closely approximated by a complex, curvilinear function. When other end-systolic P-V slope value relations were compared to the LV EF data, weak correlation coefficients were obtained with linear regression analysis of the raw data, while better correlation coefficients were observed when polynomial curve fitting was applied to the natural log transformed data. Moreover, the indirect P-V (BaP/ minV) slope value relations also demonstrated an improvement in correlation with the LV EF data with polynomial curve fitting of the natural log transformed data in comparison to linear regression analysis of the raw data. Thus despite differences in the mean isochronal $E_{\operatorname{aax}}$, end-systolic P-V relations, and indirect P.V relations, they all, except for the $(-) \mathrm{dP} / \mathrm{dtPV}$ relations, have a comparable relationship with LV shortening characteristics as measured by LV EF.

Sagawa et al. $^{3}$ suggested that knowing the endsystolic $P-V$ ratio from a single beat, one can theoretically predict LV stroke volume or EF if LV end-diastolic volume and end-systolic pressure are known. The LV EF is then equivalent to: $\mathrm{EF}=1-\left[\mathrm{ESP} / \operatorname{EDV}\left(\mathrm{E}_{\max }\right)\right]-\mathrm{V}_{\mathrm{o}} / \mathrm{EDV} ; \quad$ where $\mathrm{ESP}=$ end-systolic pressure, $\mathrm{EDV}=$ end-diastolic volume, $\mathrm{V}_{\mathrm{O}}=$ the unstressed volume, and $\mathrm{E}_{\max }$ in this construct is the end-systolic $\mathrm{P}-\mathrm{V}$ ratio obtained from a single beat. The value $V_{0} / E D V$ is presumed to be 


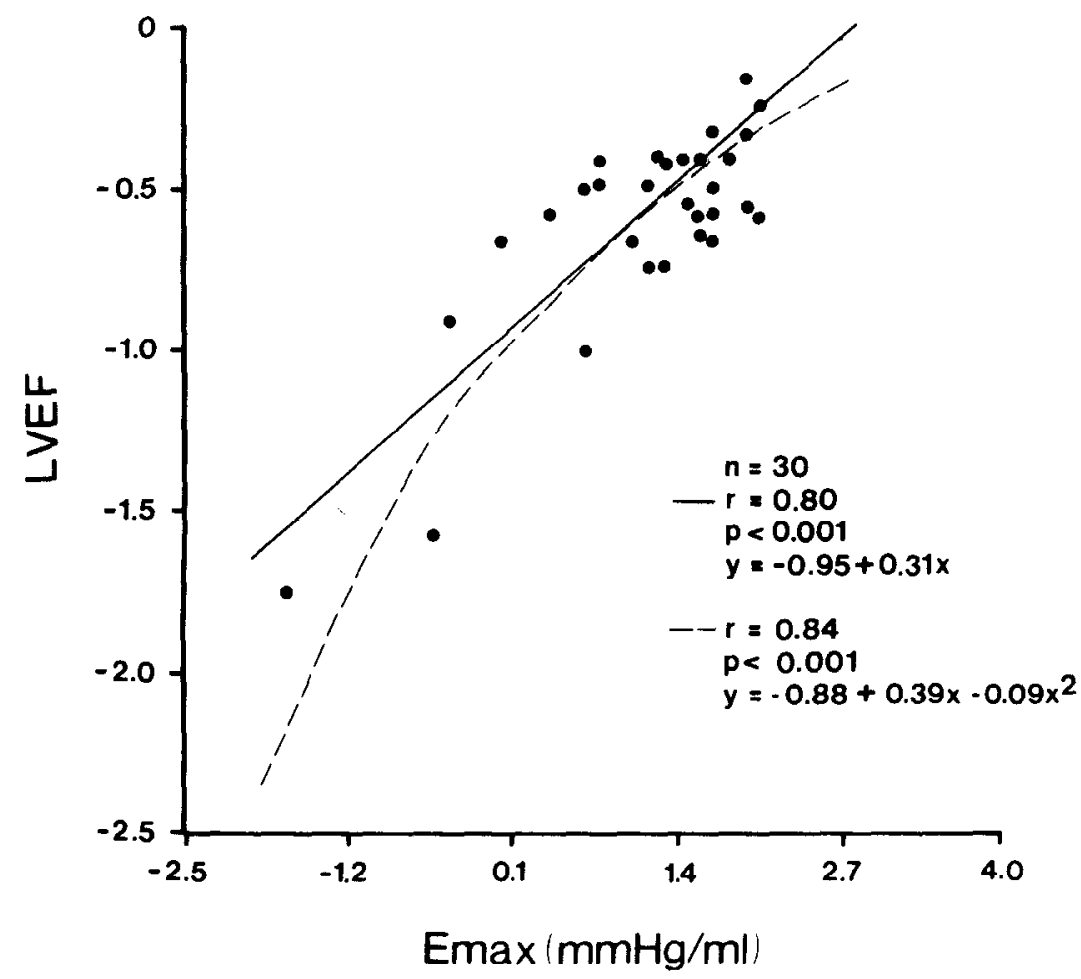

Fig. 4. The natural $\log$ transformed left ventricular ejection fraction ( $L V E F$ ) values (on the ordinate) and the natural $\log$ transformed isochronal $\mathrm{E}_{\max }$ slope values (on the abscissa) are compared by both a linear regression analysis and a polynomial curve fit. The lines of best fit for the linear regression analysis (solid line) and for the polynomial curve fit (dashed line) are shown with their correlation coefficients $(r)$ and regression equations.

negligible. When this relationship was plotted, a nonlinear relationship was constructed that was relatively insensitive to changes in the end-systolic $P-V$ ratio at high values of $L V E F$. Thus the theoretic relationship between the single beat endsystolic P.V ratio and LV EF would appear (based on this mathematical analysis) to be a complex, curvilinear function.

The data regarding the relationship between $\mathrm{LV}$ contractile state and EF in man are conflicting. ${ }^{7,11,12}$ Nivatpumin et al. ${ }^{7}$ have shown in man that the maximal P-V ratio obtained from a single beat (as predicted by Sagawa et al. ${ }^{3}$ ) has a curvilinear relationship with LV EF. This measure, however, may be sensitive to changes in loading conditions in addition to contractile state. ${ }^{8-10}$ Kono et al. ${ }^{8}$ in an excised, supported LV preparation, and Wiesenbaugh et al.,9 in an acute canine preparation, both demonstrated that the single-beat maximal P-V ratio and stress-volume ratio, since they presume a zero volume-axis intercent, increase when arterial load is increased. This has also been suggested in man. ${ }^{10}$ These single-beat ratios may also be dependent upon end-systolic volume. ${ }^{18,19}$ Thus since the maximal P-V ratio calculated from a single beat and
LV EF are sensitive to alterations in loading conditions, ${ }^{20,21}$ end-systolic P.V relations, which are characterized by both a slope and $V_{0}$ calculated from multiple data points and are independent of loading conditions, should be used to assess LV contractile state in man.

Other studies in $\operatorname{man}^{11,12}$ have compared endsystolic P-V slope value relations to LV EF. Mehmel et al. ${ }^{11}$ reported correlation coefficients between the slope of the maximum end-systolic P-V relations and LV EF when a linear $(r=0.89)$ and exponential analysis was employed $(r=0.94)$. Although no difference between these correlation coefficients was evident, they noted that the linear regression analysis did not incorporate lower LV EF values, which were incorporated by the monoexponential function. The equally high correlation coefficients for both mathematical data transformations reported by these authors may be due to the relatively few data points in the low $\mathrm{LV}$ contractile state and EF ranges.

More recently, McKay et al. ${ }^{12}$ calculated the LV maximum time-varying elastance with radionuclide angiography and demonstrated a correlation of $r=0.67$ between isochronal $\mathrm{E}_{\max }$ slope values and 
LV EF. Our data confirm this relatively weak linear correlation between the isochronal $\mathrm{E}_{\max }$ slope values and LV shortening characteristics. Other end-systolic $P$-V relations and indirect pressure-volume relations also demonstrated weak linear correlations with $\mathrm{LV} \mathrm{EF}$. Interestingly, the (-)dP/dtPV relations showed no significant correlation with LV EF, which is similar to the finding reported by McKay et al. ${ }^{12}$ This linear relationship, however, does not incorporate the lower LV EF values, as evidenced in our data by a y-axis intercept of $41 \%$. When we used a more sophisticated mathematical data transformation, the correlation coefficients between the isochronal $\mathrm{E}_{\max }$, other end-systolic P-V and indirect P.V slope value relations and LV EFs improved significantly. Thus these data demonstrate in man that the slope values of various measures of $\mathrm{LV}$ contractile state and EF are not optimally described by a linear function, but rather are more closely approximated by a complex, curvilinear function.

There may be several possible explanations for these observations. First, there is a relatively wide range of $\mathrm{LV}$ contractile states within the normal $\mathrm{LV}$ EF range (50\% to $75 \%$ ). These data suggest that $\mathrm{LV}$ EF is a poor index of contractile state. Only when $\mathrm{LV}$ contractile state is severely depressed will a reduced EF be manifest. Conversely, when LV EF is within the normal range, $L V$ contractile state may be depressed. This is not surprising, considering the load dependence of LV EF . ${ }^{20,21}$ Moreover, these data suggest that isochronal $E_{\max }$ and the other $\mathrm{P}-\mathrm{V}$ relations may be more sensitive to alterations in $\mathrm{LV}$ contractile state than shortening characteristics. This has indeed been demonstrated in an intact animal preparation ${ }^{6}$ and in a preliminary fashion in man. ${ }^{22}$ Second, these observations may also be due in part to the variability of the radionuclide LV EF determinations within the normal range. ${ }^{23,24}$ Third, this range of isochronal $\mathrm{E}_{\max }$ slope values in normal subjects and in patients with cardiovascular disease processes may be due in part to the independent influence of heart size on these LV contractile measures. ${ }^{5,13,25}$ It therefore reinforces the suggestion by Sagawa ${ }^{5}$ that for valid comparisons of $L V$ contractile state to be made between patient groups methods must be identified to standardize these slope values, thereby minimizing their range and thus enabling depressed LV contractile states to be detected in individual patients. Methods of performing this standardization have been demonstrated in animals ${ }^{25}$ and in man by means of invasive techniques. ${ }^{9}$ Thus measures of LV contractile state may be most useful in assessing patients with disease processes such as mitral regurgitation, ${ }^{18,19}$ in whom shortening characteristics may remain normal despite depressed LV contractile state because of favorable alterations in loading conditions. Finally, once slope values of the various measures of $\mathrm{LV}$ contractile state become severely depressed, the LV ejection fractions demonstrate a wide range of values. This suggests that the reflex neurohumoral adjustments to LV contractile depression and their resultant effects on loading conditions may become increasingly important for establishing the absolute value of $\mathrm{LV} \mathrm{EF}$.

Potential limitations of the present investigation should be considered. First, we assumed that a constant inotropic background existed during the three loading conditions. We observed no significant change in heart rate during the three loading conditions due to right atrial pacing. In contrast, we did observe an increase in $(+) \mathrm{dP} / \mathrm{dtmax}$ during the methoxamine infusion compared to control. This may be due to the preload dependence of $(+) \mathrm{dP} /$ dtmax. ${ }^{20,21}$ Nevertheless, since we did not automatically block our patients in this investigation, we cannot totally exclude minor alterations in autonomic tone, which may have affected the calculation of LV contractile state. Second, we assumed that the various measures of $\mathrm{LV}$ contractile state were linear over the range of loading conditions employed in this investigation. Although other investigators ${ }^{26,27}$ have also assumed linearity, recent data ${ }^{28-31}$ have suggested that these relations may not be linear in the high LV pressure range and that they may become curvilinear in the subphysiologic LV pressure range. At least within the LV pressure range we employed in this investigation, the three P-V data points for each of the definitions of end systole demonstrated linearity. Third, although we demonstrated differences in the mean slope values for other more commonly defined measures of end systole and isochronal $\mathrm{E}_{\max }$, the relationship between the slope of these end-systolic P-V relations and LV $\mathrm{EF}$ was comparable to that for isochronal $\mathrm{E}_{\max }$. The one exception was the $(-) \mathrm{dP} / \mathrm{dtPV}$ relations, which may be due in part to the difficulty in defining the exact timing of peak (-)dP/dt over the full range of loading conditions when the methods employed in this investigation are used. The definition of end systole may differ in patients with valvular heart disease compared to patients with other pathologic processes or normal subjects. It is important to note therefore that a number of our patients did have mitral and aortic regurgitation, and they were included in our patient population to establish this relationship. Finally, differences in the end-systolic and indirect $P-V$ relation and $E_{\max }$ slope values are probably multifactorial. Reasons for this may 
include the methods of altering load, the presence of intact autonomic reflexes, or the effects of increased load on the slope of the P-V relationship. ${ }^{13}$ Nevertheless, irrespective of the underlying pathologic process or the measure of $\mathrm{LV}$ contractile state, it appears that a characteristic, complex, curvilinear relationship exists between $L V$ contractile state and shortening characteristics.

In conclusion, the relationship between LV contractile state and EF is probably not linear. Rather, measures of $L V$ contractile state have a characteristic, complex, curvilinear relationship with EF. The end-systolic P-V relationship may therefore be most useful for detecting alterations in $\mathrm{LV}$ contractile state in patients who have otherwise preserved shortening characteristics such as mitral regurgitation. ${ }^{10,20}$

We appreciate the assistance of Sheila Squicciarini and the manuscript preparation by Diane Bauer, Peggy Avery, and Valerie Maier.

\section{REFERENCES}

1. Suga H, Sagawa $K$, Shoukas AA. Load independence of the instantaneous pressure-volume ratio of the canine left ventricle and effects of epinephrine and heart rate on the ratio. Circ Res 1973;32:314-22.

2. Suga $H$, Sagawa K. Instantaneous pressure-volume relationships and their ratio in the excised, supported canine left ventricle. Circ Res 1974;35:117-26.

3. Sagawa K, Suga H, Shoukas AA, Bakalar KM. End-systolic pressure/volume ratio: a new index of ventricular contractility. Am J Cardiol 1977;40:748-53.

4. Sagawa $K$. The end-systolic pressure-volume diagram revisited. Circ Res 1978;43:677-87.

5. Sagawa K. The end-systolic pressure-volume relation of the ventricle: definition, modifications and clinical use. Circulation 1981;63:1223-7.

6. Sodums MT, Badke FR, Starling MR, Little WC, O'Rourke RA. Evaluation of left ventricular contractile performance utilizing end-systolic pressure-volume relationships in conscious dogs. Circ Res 1984;54:731-9.

7. Nivatpumin T, Katz S, Scheuer J. Peak left ventricular systolic pressure/end-systolic volume ratio: a sensitive detector of left ventricular disease. Am J Cardiol 1979;43:969-74.

8. Kono A, Maughan WL, Sunagawa K, Hamilton K, Sagawa K, Weisfeldt ML. The use of left ventricular end-ejection pressure and peak pressure in the estimation of the end-systolic pressure-volume relationship. Circulation 1984;70:1057-65.

9. Wisenbaugh T, Yu G, Evans J. The superiority of maximum fiber elastance over maximum stress-volume ratio as an index of contractile state. Circulation 1985;72:648-53.

10. Starling MR, Walsh RA. Load dependence of the maximum stress-volume ratio in man [Abstract]. Clin Res 1986; 34:346A.

11. Mehmel HC, Stockins B, Ruffmann K, Olshausen KV, Schuler G, Kubler W. The linearity of the end-systolic pressurevolume relationship in man and its sensitivity for assessment of left ventricular function. Circulation 1981;63:1216-22.

12. McKay RG, Aroesty JM, Heller GV, Royal HD, Warren SE, Grossman W. Assessment of the end-systolic pressurevolume relationship in human beings with the use of a time-varying elastance model. Circulation 1986;74:97-104.

13. Starling MR, Walsh RA, Dell'Italia L.J, Mancini GBI, Lasher JC, Lancaster JL. The relationship of various measures of end-systole to left ventricular maximum time-varying elastance in man. Circulation 1987;76:32-43.

14. Starling MR, Dell'Italia LJ, Walsh RA, Little WC, Benedetto AR, Nusynowitz ML. Accurate estimates of absolute left ventricular volumes from equilibrium radionuclide angiographic count data using a simple geometric attenuation correction. J Am Coll Cardiol 1984;3:789-98.

15. Starling MR, Dell'Italia LJ, Nusynowitz ML, Walsh RA, Little WC, Benedetto AR. Estimates of left-ventricular volumes by equilibrium radionuclide angiography: importance of attenuation correction. J Nucl Med 1984;25:14-20.

16. Links JM, Becher LC, Shindledecker JG, et al. Measurement of absolute left ventricular volume from gated blood pool studies. Circulation 1982;65:82-91.

17. Radiological Health Handbook. Washington, D.C.: U.S. Department of Health, Education and Welfare, Public Health Service, January 1970:133.

18. Carabello BA, Nolan SP, McGuire LB. Assessment of preoperative left ventricular function in patients with mitral regurgitation: value of the end-systolic wall stress-end-systolic volume ratio. Circulation 1981;64:1212-17.

19. Carabello BA, Williams H, Gash AK, Kent R, Belher D, Maurer A, Siegel J, Blasius K, Spann JF. Hemodynamic predictors of outcome in patients undergoing valve replacement. Circulation 1986;74:1309-16.

20. Quinones MA, Gaasch WH, Alexander JK. Influence of acute changes in preload, afterload, contractile state and heart rate on ejection and isovolumic indices of myocardial contractility in man. Circulation 1976;53:293-302.

21. Mahler F, Ross J Jr, O'Rourke RA, Covell JW. Effects of changes in preload, afterload and inotropic state on ejection and isovolumic phase measures of contractility in the conscious dog. Am J Cardiol 1975;35:626-34.

22. Starling MR. Application of radionuclide maximum timevarying elastance to detection of enhanced left ventricular contractile function in man [Abstract]. Clin Res 1987; 35:879A.

23. Folland ED, Hamilton GW, Larson SM, Kennedy JW, Williams DI., Ritchie JI. The radionuclide ejection fraction: a comparison of three radionuclide techniques with contrast angiography. J Nucl Med 1977;18:1159-65.

24. Wackers FJT, Berger HJ, Johnstone DE, Goldman L, Reduto LA, Langon RA, Gottschalk A, Zaret BL. Multiple gated cardiac blood pool imaging for left ventricular ejection fraction: validation of the techmique and assessment of variability. Am J Cardiol 1979;43:1159-64.

25. Belcher P, Boerboom LE, Olinger GN. Standardization of end-systolic pressure-volume relations in the dog. Am J Physiol 1985;249:H547-53.

26. Grossman W, Braunwald E, Mann T, McLaurin LP, Green LH. Contractile state of the left ventricle in man as evaluated from end-systolic pressure-volume relations. Circulation 1977;56:845-52.

27. Pouleur H, Rousseau MF, Eyll CV, Mechelen HV, Brasseur LA, Charlier AA. Assessment of left ventricular contractility from late systolic stress-volume relations. Circulation 1982; 65:1204-12.

28. Suga H, Yamada O, Goto Y, Igarashi Y. Peak isovolumic pressure-volume relation of puppy left ventricle. Am J Physiol 1986;250:H167-72.

29. Freeman GL, Little WC, O'Rourke RA. The effect of vasoactive agents on the left ventricular end-systolic pressurevolume relation in closed-chest dogs. Circulation 1986; 74:1107-15.

30. Sunagawa K, Maughan WL, Friesinger G, Guzman P, Chang MS, Sagawa K. Effects of coronary arterial pressure on left ventricular end-systolic pressure-volume relations of isolated canine heari. Circ Res 1982; $50: 727-34$.

31. Elzinga G, Westerhoff N. Does the history of contraction affect the pressure-volume relationship? Fed Proc 1984; 43:2402-07. 